\title{
Preinoculation Effects of Light Quantity on Infection Efficiency of Puccinia striiformis and P. triticina on Wheat Seedlings
}

\author{
C. de Vallavieille-Pope, L. Huber, M. Leconte, and O. Bethenod
}

First and third authors: Unité de Pathologie Végétale et Epidémiologie, I.N.R.A., BP 01, 78850 Thiverval-Grignon, France; and second and fourth authors: Unité Mixte de Recherche Environnement et Grandes cultures, I.N.R.A.-I.N.A-P.G., BP 01, 78850 Thiverval-Grignon, France.

Accepted for publication 31 July 2002.

\begin{abstract}
de Vallavieille-Pope, C., Huber, L., Leconte, M., and Bethenod, O. 2002. Preinoculation effects of light quantity on infection efficiency of Puccinia striiformis and P. triticina on wheat seedlings. Phytopathology 92:1308-1314.

In a previous study under controlled conditions, a model was developed to predict the infection efficiency for the wheat leaf and stripe rust fungi based on temperature and dew period during the $24 \mathrm{~h}$ after inoculation. The two pathogens differed in their maximum infection efficiency under controlled conditions for temperature and dew period, the infection efficiency was 12 times greater for Puccinia triticina than for $P$. striiformis. In the present study, the model was validated by field results to predict $P$. triticina infection efficiency as a function of temperature and dew period only. However, this model failed to predict infection efficiency caused by $P$. striiformis in the field. The model was adapted to include the effects of light quantity on infection efficiency.
\end{abstract}

ABSTRACT

The progress of epidemics of polycyclic diseases depends on the values of the variables that control the monocyclic phase of the disease, which are influenced by meteorological conditions and host susceptibility. Whether a pathogen causes a significant epidemic is dependent on the number of infection cycles the pathogen is able to complete during a season. Microclimatic conditions such as temperature, dew period, and light intensity greatly influence the development of rust on cereal plants (37). Monocyclic phases of wheat (Triticum aestivum L.) rust pathogens, Puccinia striiformis West. (stripe (yellow) rust) and P. triticina Eriks. (=P. recondita Rob. ex Desm. f. sp. tritici Eriks \& Henn.) (leaf (brown) rust) (2) have been investigated and include studies on the influence of temperature on the latent period $(19,39)$, the effect of temperature and dew period on infection efficiency (8), and the effect of rain on spore dispersal (15). In some studies of different diseases, monocyclic variables have been estimated only under controlled conditions (23), but models derived from the experimental data have not been validated under field conditions so these models should be used with caution in forecasting development of diseases.

In controlled-environment experiments, we found the maximum infection efficiency for $P$. triticina (43.6\%) was 12 times that of $P$. striiformis (4\%) (8). Low infection efficiencies (1 to 7\%) have been commonly observed for $P$. striiformis under controlled conditions of temperature and dew period $(4,8,13,22,26,27)$, but some studies have reported $P$. striiformis infection efficiencies to be in the range of 10 to $20 \%(14,21,31)$. In comparison, $P$. triticina

Corresponding author: C. de Vallavieille-Pope; E-mail address: pope@grignon.inra.fr

Publication no. P-2002-1015-01R

(C) 2002 The American Phytopathological Society
Wheat seedlings, grown in climate-controlled rooms and exposed to various regimes of light duration and intensity for $24 \mathrm{~h}$ in either field or controlled conditions, were inoculated and incubated in climate-controlled rooms under optimal dew and temperature conditions. Quantity of natural or artificial light (light intensity $\times$ duration) received by the plants prior to inoculation enhanced infection efficiency of wheat seedlings inoculated by $P$. striiformis. Infection efficiency increased from 0.4 to $36 \%$ depending on the light quantity according to a Richards' function. For stripe rust, three environmental variables, preinoculation light quantity received by the plants, postinoculation temperature, and postinoculation dew period, were used for fitting a model for infection efficiency measured in the field.

Additional keywords: dew period, host receptivity, leaf (brown) rust, modeling, monocyclic parameters, stripe (yellow) rust, temperature.

infection efficiencies have been reported to be greater than $20 \%$ $(16,24,26,34)$ and commonly over $30 \%(6,8,11,30,31)$. Temperature and dew period data (8) have been used to successfully estimate the occurrence of infection of $P$. triticina in the field (9), whereas field results have contradicted the low infection efficiencies of $P$. striiformis observed under controlled conditions. Periods favoring infection by $P$. striiformis occurred regularly, even during the summer when the temperature was high $(25,38)$, and as suggested by controlled-environment experiments, high temperature is a limiting factor $(8,10)$. This suggests that other external factors may influence $P$. striiformis infection efficiency. Radiation levels in controlled environments are usually much lower than in the field. Furthermore, under field conditions, $P$. striiformis often had higher infection efficiencies than predicted by the model (8) when the temperatures were high, and the plants had received long periods of sunlight. These observations led us to test the hypothesis that the light quantity received by the plants before inoculation was a major factor in modulating $P$. striiformis infection efficiency.

Here we report field experiments on infection efficiency of both rusts to assess the validity of a previously published model based on controlled-environment experiments for temperature and dew period (8). We also report controlled environment and field studies on the influence of preinoculation light quantity on infection efficiency of $P$. striiformis, and the modification of a model (8) to account for the observed effects.

\section{MATERIALS AND METHODS}

Fungi, plants, inoculation, and incubation. Single urediniospore isolates of both fungi collected in France (isolate J89108, race 232E137 of $P$. striiformis (7) and isolate B8620-3 of $P$. 
triticina) were used. The fungi were maintained on 10-day-old wheat seedlings of the highly susceptible cv. Michigan Amber. Spores were produced in a controlled-environment room with an 8 -h $14^{\circ} \mathrm{C}$ dark period and a 16 -h $17^{\circ} \mathrm{C}$ light period with a light intensity of $300 \mu \mathrm{mol}$ quanta $\mathrm{m}^{-2} \mathrm{~s}^{-1}$. Eleven and 15 days after inoculation of plants with $P$. triticina and $P$. striiformis, respectively, urediniospores were harvested and placed in a glycerol filled desiccator for 4 days at $5^{\circ} \mathrm{C}$ and stored in liquid nitrogen. Spores were heat chocked at $40^{\circ} \mathrm{C}$ for $10 \mathrm{~min}$ before inoculation.

Ten seeds of cv. Michigan Amber per 7-cm pot were sown and grown in an air-filtered chamber inside a greenhouse maintained at 15 to $20^{\circ} \mathrm{C}$. When the plants were 10- to 12-day-old (two-leaf stage, growth stage 12) (40), six seedlings per pot were selected for homogeneity of development and the other four were discarded. The second leaf from the top of each plant was excised. The inoculation was made on the first leaf, which was attached horizontally with its adaxial side up to a plexiglass sheet using plasticine (Ulmann, Paris, France). Plants in 10 pots were inoculated together in a settling tower (12) using $1 \mathrm{mg}$ of urediniospores, which resulted in a deposit of $115 \pm 10$ urediniospores per $\mathrm{cm}^{2}$ on the leaves. After inoculation, plants were either placed outdoors overnight (experiment 1) or in a climate-controlled room where the plants were covered with polyethylene bags to ensure dew formation and placed in the dark for $24 \mathrm{~h}$ at $8^{\circ} \mathrm{C}$, which is the optimal conditions for penetration for $P$. striiformis (experiments 2 and 3 ). In the three experiments, all pots were placed in a climatecontrolled room with conditions conducive to incubation $\left(14^{\circ} \mathrm{C}\right.$ for an 8 -h dark period and $17^{\circ} \mathrm{C}$ for a 16 -h light period with a light intensity of $300 \mu \mathrm{mol}$ quanta $\mathrm{m}^{-2} \mathrm{~s}^{-1}$ ) for 11 days for $P$. triticina (until sporulating pustules developed) and 7 days for P. striiformis (until chloroses appeared).

Experiment 1: effects of postinoculation temperature and dew duration. Ten pots of six 10- to 12-day-old seedlings grown in the greenhouse were inoculated as described above. Five control pots were placed in controlled conditions of temperature and wetness optimal for penetration $\left(24 \mathrm{~h}\right.$ at 15 and $8^{\circ} \mathrm{C}$ for $P$. triticina and $P$. striiformis, respectively), and five pots were placed in the field (INRA station, Grignon, France) overnight from 5 P.M. until 9 A.M. After $16 \mathrm{~h}$ under field conditions, free water on the leaves was evaporated within 5 min by placing the pots under a fume exhaust hood (30 to $40 \%$ relative humidity, $20^{\circ} \mathrm{C}$ ). All 10 pots were placed in a climate-controlled room with conditions conducive to incubation $\left(14^{\circ} \mathrm{C}\right.$ for an 8 -h dark period and $17^{\circ} \mathrm{C}$ for a 16-h light period with a light intensity of $300 \mu \mathrm{mol}$ quanta $\mathrm{m}^{-2} \mathrm{~s}^{-1}$ ). Experiment 1 was done in the spring and autumn, which are the two seasons favorable to epidemic development. Fifty-three tests were done with leaf rust and 63 with stripe rust.

Leaf temperature $\left( \pm 0.1^{\circ} \mathrm{C}\right)$ and leaf wetness duration in the field were recorded as $15 \mathrm{~min}$ averages using a data logger (21X, Campbell Scientific LTD, Shepshed, Leicestershire, England). Leaf temperature was measured using copper-constantan thermocouples, leaf wetness duration was measured using leaf wetness sensors (Model 237, Campbell Scientific), and rainfall was measured using a mechanical rain gauge (Précis Mécanique, Bezons, France). The light quantity received by plants was not intended to be a variable when experiment 1 was set up. The results obtained in experiment 2 led us to analyze the effects of light quantity received by plants $24 \mathrm{~h}$ before spore penetration was possible (i.e., after dew formation in the field). The light quantity received by plants $24 \mathrm{~h}$ before dew formation was the sum of the light quantity received in the greenhouse (before the transfer to the field) and the light quantity received in the field (from 5 P.M. until sunset). The light quantity received by plants in the greenhouse (qi) was calculated using outside measurements (qe) with a quantum sensor ( $\mathrm{Li}$ Cor, Lincoln, NE). The outside measurements were corrected using a relationship previously established between qe and qi (qi = $\left.0.46+\left\{2.19 /\left[1+\left(12.4 \mathrm{qe}^{2}\right)\right]\right\}, r=0.99\right)$. The light quantity re- ceived in the field was estimated using global radiation measurements (pyranometer CE180, Cimel Electronique, Paris, France) from a standard weather meteorological station $15 \mathrm{~km}$ away.

Experiment 2: effects of preinoculation light intensity under controlled conditions. Seven-day-old seedlings grown in the greenhouse were placed at $8^{\circ} \mathrm{C}$ for 3 days under low light intensity $\left(45 \mu \mathrm{mol}\right.$ quanta $\mathrm{m}^{-2} \mathrm{~s}^{-1}$ with a photoperiod of $16 \mathrm{~h}$ of light and $8 \mathrm{~h}$ of dark) followed by a 16-h dark period before exposing them to different light treatments. Preinoculation light treatments were done in a $2 \mathrm{~m}^{3}$ (2 $\mathrm{m}$ high) climate-controlled room (L'Aurore, Charenton, France) with a semiclosed gas exchange system. The system allowed $\mathrm{CO}_{2}$ concentration and humidity to be kept at fixed values for given temperatures. The lighting system consisted of 10 400-W discharge lamps (HQI, Osram, München, Germany) mounted with five lamps facing each other. Plants were placed $1 \mathrm{~m}$ below the lamps. Before inoculation, seedlings were exposed to 22 different combinations of light duration $(0,1,2,4,6,9,10,11,14,15$, and $16 \mathrm{~h})$ and light intensity $(0$, $2,4,6$, and 8 lamps) to give a range of light quantity ( 0 to 33 mol quanta $\mathrm{m}^{-2}$ ). The light quantity received per $\mathrm{h}$ at the top of the seedlings with $2,4,6$, and 8 lamps was $0.49,0.92,1.44$, and 2.02-mol quanta $\mathrm{m}^{-2}$, respectively. For each combination of light duration and light intensity, control plants were kept in the dark for $16 \mathrm{~h}$ before inoculation. After light exposure, the plants were inoculated and incubated under optimal controlled conditions of penetration and incubation $\left(24 \mathrm{~h}\right.$ at $8^{\circ} \mathrm{C}$ in the dark and 7 days at $14^{\circ} \mathrm{C}$ for an 8 -h dark period and $17^{\circ} \mathrm{C}$ for a 16 -h light period with a light intensity of $300 \mu \mathrm{mol}$ quanta $\mathrm{m}^{-2} \mathrm{~s}^{-1}$ ). Each of the $22 \mathrm{com}-$ binations had 10 pots of six plants and was repeated twice. Difference in light intensities between the two replicates was less than $5 \%$.

During the preinoculation light treatment in the climate-controlled room (L'Aurore), temperature and dew point were regulated using sensors placed $0.8 \mathrm{~m}$ above the plants. Temperature, humidity, and light intensity were measured every $10 \mathrm{~s}$ by a data logger (CR10, Campbell Scientific). Temperature was maintained at $20 \pm 1.5^{\circ} \mathrm{C}$ and measured using copper-constantan thermocouples. Relative humidity was maintained at $60 \%$ and measured using a psychrometer (HMP 35D, Vaisala, Sweden). Photon flux density was measured using a quantum sensor (Li-Cor). The results were recorded as 15 -min averages.

Experiment 3: effects of preinoculation light intensity in the field. The plants were grown in the greenhouse for 7 days and then in a climate-controlled room at $8^{\circ} \mathrm{C}$ for 3 days under low light intensity ( $45 \mu \mathrm{mol}$ quanta $\mathrm{m}^{-2} \mathrm{~s}^{-1}$ with a photoperiod of $16 \mathrm{~h}$ of light and $8 \mathrm{~h}$ of dark) before being exposed to different light treatments. Preinoculation light treatments consisted of exposure of seedlings to different light levels by leaving them in full sunlight or placing them in the shade. The shaded plants were placed under a plastic net (1-mm mesh size, Moustiquaire plastique, Nortène MMOU3V, Castorama, Paris, France) that reduced light intensity by a factor of three. Four groups of 10 pots each were placed outdoors, two in the shade and two in full sunlight. Plants were placed outdoors at 5 P.M., and two groups (one shaded, one unshaded) were returned to the laboratory the following day at 11 A.M. and the remaining two groups were returned at 4.30 P.M. The preinoculation light quantity received by the plants was assessed from sunrise until 11 A.M. or 4.30 P.M. After the light exposure, the plants were returned to the laboratory, inoculated by $P$. striiformis and placed under optimal conditions for penetration and incubation $\left(24 \mathrm{~h}\right.$ at $8^{\circ} \mathrm{C}$ in the dark and 7 days at $14^{\circ} \mathrm{C}$ for an 8 -h dark period and $17^{\circ} \mathrm{C}$ for a 16 -h light period with a light intensity of $300 \mu \mathrm{mol}$ quanta $\mathrm{m}^{-2} \mathrm{~s}^{-1}$ ). Ten pots, used as a reference for minimum infection level with a dark period before inoculation, were placed in a climate-controlled room at $8^{\circ} \mathrm{C}$ in the dark for $16 \mathrm{~h}$. Seven tests were done in the May to June period. Leaf temperature and light intensity at leaf level were recorded using a data logger. 
Infection. Infection was assessed by counting the number of sporulating pustules of $P$. triticina 11 days after inoculation. Because the lesions of $P$. striiformis grow systemically within the leaf, $P$. striiformis infection was estimated before the pustules could collapse by counting the number of chloroses on the inoculated area 7 days after inoculation. Infection efficiency was calculated as the number of pustules ( $P$. triticina) or chloroses $(P$. striiformis) per leaf area divided by the number of spores deposited per leaf area (115 urediniospores per $\mathrm{cm}^{2}$ ). The number of pustules and chloroses was counted on a 4- to $5-\mathrm{cm}^{2}$ area in the middle of each leaf. Leaf area was calculated from length and width at midlength measurements in the tested zone on each leaf.

Data analysis and modeling. Experiment 1 data were analyzed using Models 0 and 1. Model 0, de Vallavieille-Pope et al. (8), describes infection efficiency (IE) as a function of temperature $(T)$ and dew period $(D P)$ only. Model 1 was a modified version of Model 0 with the effect of light intensity $(L)$ on IE being added. In Model 1, IE $(L, T, D P)$ was described as the product of maximum infection efficiency $\mathrm{IE}_{\max }$ (i.e., IE under optimal conditions of temperature, dew period, and light intensity) and three relative
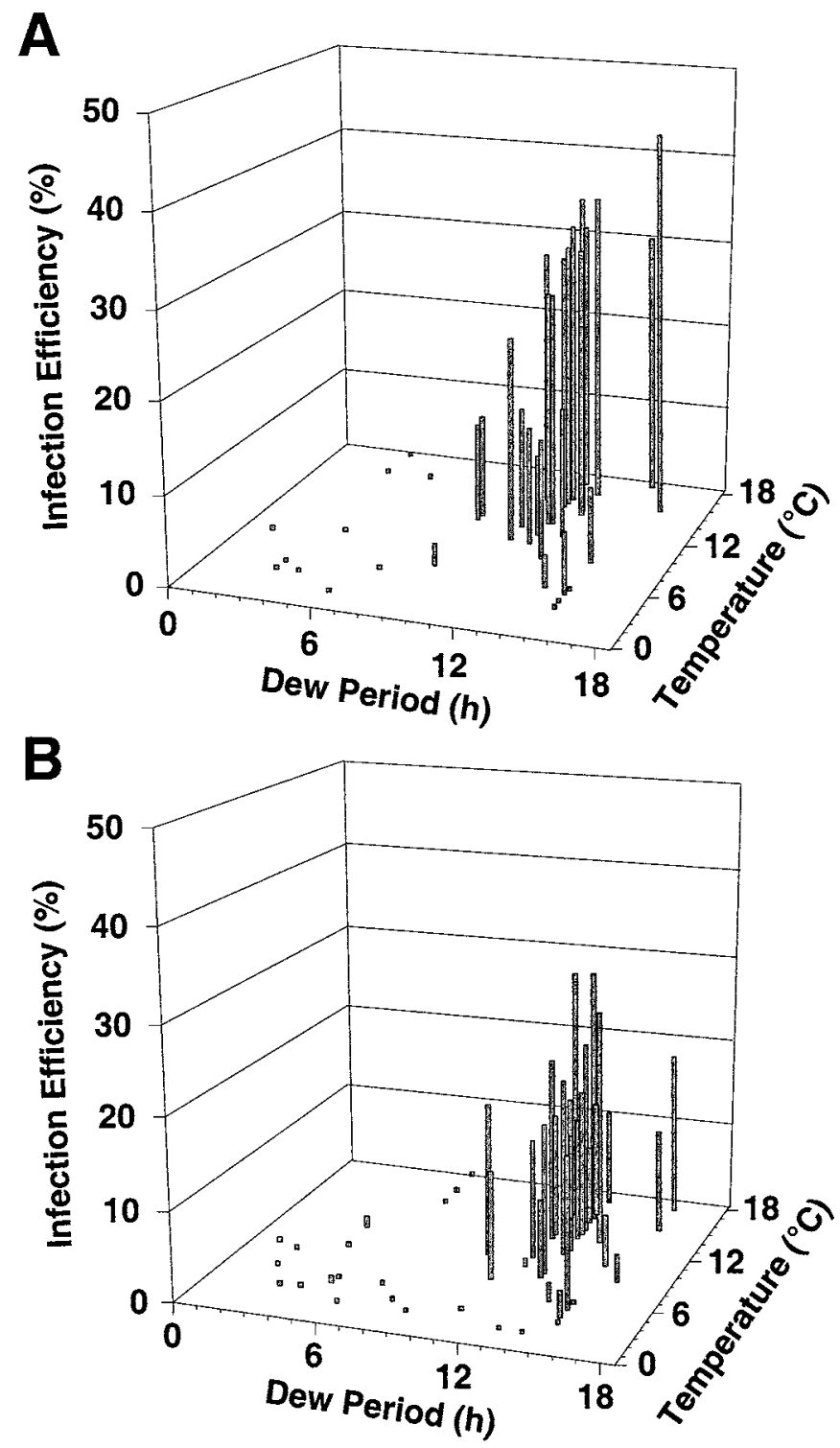

Fig. 1. Infection efficiency for $\mathbf{A}$, leaf rust (Puccinia triticina) and $\mathbf{B}$, stripe rust ( $P$. striiformis) observed in field experiment 1 as a function of temperature and dew period during the $16 \mathrm{~h}$ after inoculation. Only tests with no rain (39 tests for leaf rust and 49 for stripe rust) are presented. infection functions (RIE); one each for light $(L)$, temperature $(T)$ and dew period $(D P)$

$$
\operatorname{IE}(L, T, D P)=\operatorname{IE}_{\max } \times \operatorname{RIE}(L) \times \operatorname{RIE}(T) \times \operatorname{RIE}(D P)
$$

The relative infection functions can have values between 0 and $1(\operatorname{RIE}(X)=1$ when the variable $X$ is not limiting). Model 0 was also described by equation 1 with $\operatorname{RIE}(L)=1$. $\operatorname{RIE}(L)$ was assumed to follow a Richards' function with temperature-independent parameters, $c$ and $d$

$$
\operatorname{RIE}(L)=\{1-\exp [-c(L+d)]\}
$$

For optimal temperature for infection and nonlimiting dew period, $\operatorname{RIE}(T)$ and $\operatorname{RIE}(D P)$ are equal to 1 . Therefore, equation 1 becomes

$$
\mathrm{IE}=\operatorname{IE}_{\max } \times \operatorname{RIE}(L)=\operatorname{IE}_{\max }\{1-\exp [-c(L+d)]\}
$$

The parameters $\mathrm{IE}_{\max }, c$ and $d$ were estimated using the IE data of experiment 2 where temperature was optimal for infection and dew period was not a limiting factor. $L$ values were measured in experiment 2 . $\mathrm{IE}_{\max }$ was equal to the asymptotic value of equation 3 .

The influence of temperature on $\operatorname{RIE}(T)$ was assumed to follow

$$
\operatorname{RIE}(T)=p\left[\left(T-T_{\min }\right) /\left(T_{\max }-T_{\min }\right)\right]^{n}\left[\left(T_{\max }-T\right) /\left(T_{\max }-T_{\min }\right)\right]^{m}
$$

where the parameters $p, T_{\min }, T_{\max }, n$, and $m$ are constants (8). For nonlimiting dew period for infection, $\operatorname{RIE}(D P)$ is equal to 1 . Therefore, equation 1 becomes

$$
\begin{gathered}
\mathrm{IE}=\mathrm{IE}_{\max } \times \mathrm{RIE}(L) \times p\left[\left(T-T_{\min }\right) /\left(T_{\max }-T_{\min }\right)\right]^{n} \\
{\left[\left(T_{\max }-T\right) /\left(T_{\max }-T_{\min }\right)\right]^{m}}
\end{gathered}
$$

To estimate the parameters $T_{\min }, T_{\max }, n$, and $m$, the 23 field tests of experiment 1 for which $D P$ was not limiting, i.e., $\operatorname{RIE}(D P)=1$, were used. The parameter $p$ was given by $p=(n+m)^{n+m} /\left(n^{n} m^{m}\right)$ (1). $\mathrm{IE}_{\max }$ was estimated previously (with experiment 2 data applied to equation 3), $\operatorname{RIE}(L)$ was calculated from measurements of $L$ in 23 tests of experiment 1 , and the parameters $c$ and $d$ were estimated previously (with experiment 2 data applied to equation 3 ).

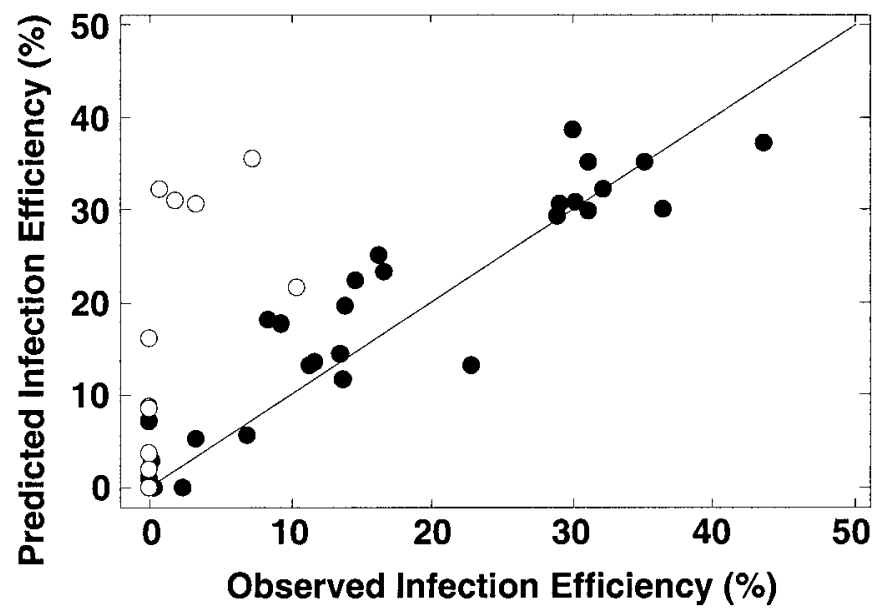

Fig. 2. Comparison of Puccinia triticina infection efficiency predicted by Model 0 with observed infection efficiency for 53 field tests (experiment 1). The parameters of Model 0 were derived from controlled-environment experiments (8). For 14 tests, the free-moisture was due to rain $(O)$, and for the other 39 tests, the wet period was caused by dew $(\bullet)$. The solid line represents $1: 1$ correspondence. The regression equation for the tests with dew was $y=1.022 x, P=0.05, r=0.94$. 
The function $\operatorname{RIE}(D P)$ was assumed to be described by (8)

$$
\operatorname{RIE}(D P)=1-\exp \left\{-b(T)\left[D P-D P_{\min }(T)\right]\right\}
$$

for $D P>D P_{\text {min }}$, where $D P_{\text {min }}(T)$ is the minimum dew period necessary for infection at temperature $T$ and $b(T)$ is the initial infection rate. For $D P<D P_{\min }, \operatorname{RIE}(D P)=0$ and there is no infection. Both $D P_{\min }(T)$ and $b(T)$ are assumed to be quadratic functions of $T$ (8). All infection efficiency values of experiment 1 were used to estimate the parameters $b$ and $D P_{\min }$ from

$$
\mathrm{IE}=\mathrm{IE}_{\max } \times \mathrm{RIE}(L) \times \mathrm{RIE}(T) \times\left\{1-\exp \left[-b(T)\left(D P-D P_{\min }(T)\right)\right]\right\}
$$

where $\operatorname{RIE}(L)$ and $\operatorname{RIE}(T)$ were calculated from $L$ and $T$ measurements in experiment 1 and values of parameters $\mathrm{IE}_{\max }, c$ and $d$ estimated previously using experiment 2 data applied to equation 3 , and values of parameters $T_{\min }, T_{\max }, n$, and $m$ estimated previously using 23 tests of experiment 1 applied to equation 5 .

In equations $1,3,5$, and $7, \mathrm{IE}_{\max }$ was equal to the asymptotic value of equation 3 , based on the data obtained in experiment 2 . In the description of experimental results, maximum infection efficiency was used to indicate the highest IE value observed in the experiment.

Statistical analyses were done using the Statistical Analysis System (SAS Institute, Cary, NC) (33). For leaf and stripe rusts, observed values of infection efficiency in field conditions (experiment 1) were compared to those predicted by Model 0 using the regression (REG) procedure. The function $\operatorname{RIE}(L)$ (equation 3 ) was fitted to a Richards' model using the nonlinear regression (NLIN) procedure with experiment 2 data. For the validation of equation 3 , observed values of infection efficiency after preinoculation light treatments in field conditions (experiment 3) were compared to those predicted by the function $\operatorname{RIE}(L)$ (equation 3 ) using the procedure REG. In order to adjust a model to stripe rust data of infection efficiency observed in the field (experiment 1), Model 0 was modified to create Model 1 following three steps and using the NLIN procedure: (i) parameterization of $\operatorname{RIE}(L)$ (equation 3) with data from experiment 2, (ii) parameterization of $\operatorname{RIE}(T)$ (equation 5) using infection efficiencies observed in experiment 1 under nonlimiting dew periods [after data smoothing using the general linear model (GLM) procedure], and (iii) parameterization of $\operatorname{RIE}(D P)$ (equation 7) using all infection

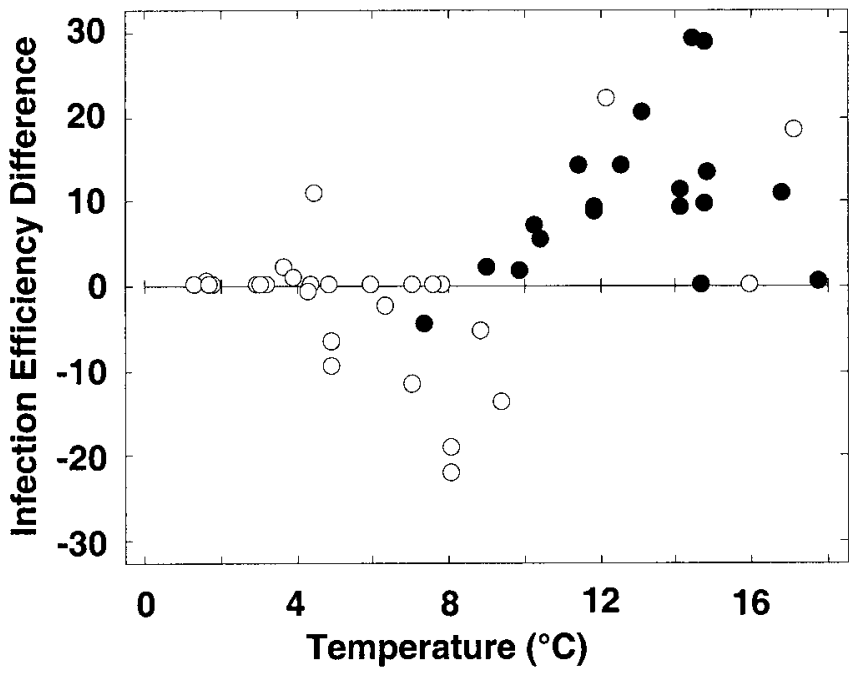

Fig. 3. Differences in Puccinia striiformis infection efficiencies between observed in field experiment 1 and predicted by Model 0 (with $\mathrm{IE}_{\max }$ set at $29 \%$, the maximum IE in experiment 1) plotted against temperature. The daylight duration received by the plants the day before inoculation was $<14 \mathrm{~h}(\mathrm{O})$ and $>14 \mathrm{~h}(\bullet)$. efficiency data from experiment 1 . For stripe rust, the fitting of Model 1 to observed values of infection efficiency in field conditions (experiment 1) was tested using the REG procedure.

\section{RESULTS}

Comparison of infection efficiency between observed and predicted for $\boldsymbol{P}$. triticina. For experiment 1 , IE was in the range of 0 to $7 \%$ in 18 tests (Fig. 1A). In 15 of the 18 tests, the mean temperatures were between 2 and $8^{\circ} \mathrm{C}$ lower than the $15^{\circ} \mathrm{C}$ optimal value. In the remaining three tests, temperature was not a limiting factor $\left(15.5\right.$ to $17.8^{\circ} \mathrm{C}$ ) but dew periods (between 3 and $5 \mathrm{~h}$ ) were shorter than the 6-h minimum dew period. In 21 other tests, IE was between 8.5 and $43.5 \%$, mean temperatures between 7.5 and $17.5^{\circ} \mathrm{C}$, and dew periods lasted longer than $9 \mathrm{~h}$. The maximum infection efficiency observed in the field was $43.5 \%$ $\left(14.5^{\circ} \mathrm{C}\right.$ and $16 \mathrm{~h}$ of dew period) and was similar to the maximum infection efficiency obtained in controlled conditions $(43.6 \%$ at $15^{\circ} \mathrm{C}$ with nonlimiting dew period) (8). There was good correlation between the observed IEs in experiment 1 and IEs predicted by the Model 0 ( $r=0.94 ;$ Fig. 2$)$. The Model 0 accurately predicted infection efficiency for the temperature range of 2 to $18^{\circ} \mathrm{C}$ and the dew period range of 0 to $16 \mathrm{~h}$.

In another 14 tests, rain occurred during the night and infection efficiency was $<10 \%$ (Fig. 2). Despite temperatures $\left(8\right.$ to $17.5^{\circ} \mathrm{C}$ ) and duration of wetness caused by rain ( 9 to $16 \mathrm{~h}$ ), which provided conditions presumably favorable for infection, the observed infection efficiency was nil or very low in seven tests. In the other seven tests, the temperature was low $\left(2\right.$ to $\left.6.5^{\circ} \mathrm{C}\right)$ or the wet period was only $1 \mathrm{~h}$, leading to very low infection as predicted by Model 0.

Comparison of infection efficiency between observed and predicted for $\boldsymbol{P}$. striiformis. In 14 tests, rain occurred and infection efficiency was in the range of 0 to $8 \%$. In the other 49 tests

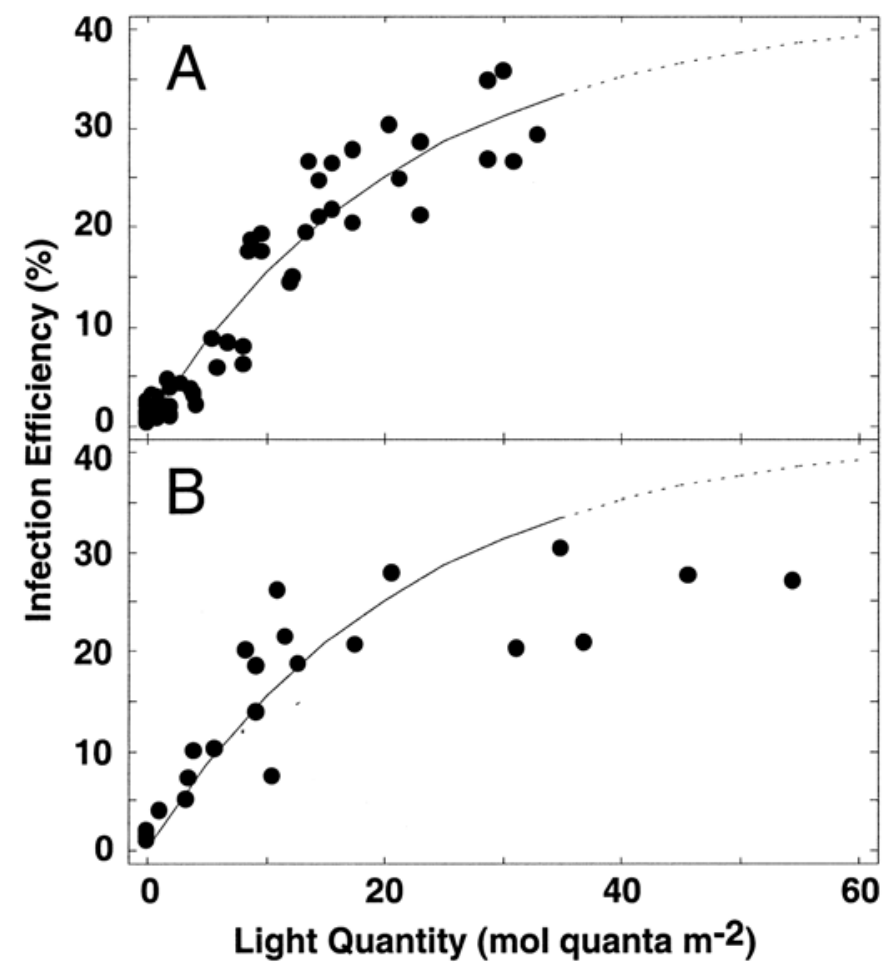

Fig. 4. Puccinia striiformis infection efficiency as a function of light quantity received by the plants before inoculation under $\mathbf{A}$, controlled-environment experiment 2 and $\mathbf{B}$, field experiment 3. A Richards' function $(\operatorname{RIE}(L)=$ $\{1-\exp [-0.045(L+0.065)]\}$ with $\mathrm{IE}_{\max }=42.1 \%$ (equation 3 ) was fitted to the data obtained in experiment $2(r=0.96)$. The fitted line in $\mathbf{A}$ is shown also in $\mathbf{B}(r=0.91)$. 
there was dew. In 14 of these tests, the dew period was less than $6 \mathrm{~h}$ and infection efficiency was less than $2 \%$ regardless of the temperature (Fig. 1B). In 11 of these tests, the dew period was more than $6 \mathrm{~h}$, the temperature was less than $5^{\circ} \mathrm{C}$, and infection efficiency was less than $3 \%$ in all but one test. In the remaining 24 tests, the dew period was more than $6 \mathrm{~h}$, the temperature was higher than $5^{\circ} \mathrm{C}$, and IE was between 6 and $29 \%$, except for one test at $1 \%$.

For dew periods less than $6 \mathrm{~h}$, Model 0 predicted no infection as observed in experiment 1 . For dew periods longer than $6 \mathrm{~h}$, the dew period was no longer a limiting factor, but low temperature $\left(<5^{\circ} \mathrm{C}\right)$ was. High values of IE were observed at temperatures between 6 and $18^{\circ} \mathrm{C}$, whereas no infections were observed above $12^{\circ} \mathrm{C}$ under controlled-environment conditions in a previous study (8). The maximum IE (29\%) observed in experiment 1 corresponded to a temperature of $14.5^{\circ} \mathrm{C}$ and $13 \mathrm{~h}$ of dew period, whereas, in a previous study in controlled conditions, the observed maximum IE was $4 \%$ and occurred at $8^{\circ} \mathrm{C}$ with a nonlimiting dew period (8). The observed values of infection were not well described by Model $0\left(r_{0}=0.22\right)$. Model 0 was run with $\mathrm{IE}_{\max }$ set at $29 \%$, the maximum IE in experiment 1 . There was still no correlation between observed and predicted values.

Model 0 tended to overestimate IE when the temperature was less than $10^{\circ} \mathrm{C}$ and underestimates it above $10^{\circ} \mathrm{C}$ (Fig. 3). Infection efficiency also tended to be overestimated when daylight lasted between 8 and $13 \mathrm{~h}$ (mainly in February, March, April, and November) and night temperatures were in the range of 5 to $10^{\circ} \mathrm{C}$. Infection efficiencies greater than predicted by Model 0 occurred mainly in May, June, and July when daylight lasted more than $14 \mathrm{~h}$ and night temperatures were between 10 and $18^{\circ} \mathrm{C}$.

Effect of preinoculation light quantity on $P$. striiformis infection efficiency. Infection efficiencies for all control plants exposed to darkness for $16 \mathrm{~h}$ before inoculation and then kept under controlled conditions optimal for penetration (temperature of $8{ }^{\circ} \mathrm{C}$ and nonlimiting dew period) were in the range of 0.4 to $2.5 \%$ for both controlled-environment experiment 2 and field experiment 3 . In experiment 2 , the maximum infection efficiency (36\%) was observed for plants that received 30.1 mol quanta $\mathrm{m}^{-2}$ over $16 \mathrm{~h}$ before inoculation, were incubated at $8^{\circ} \mathrm{C}$ and were under nonlimiting dew period conditions. Infection efficiency increased with the total light quantity $(L)$ estimated as the product of light duration and intensity (Fig. 4A). Values of $L$ of more than $15 \mathrm{~mol}$

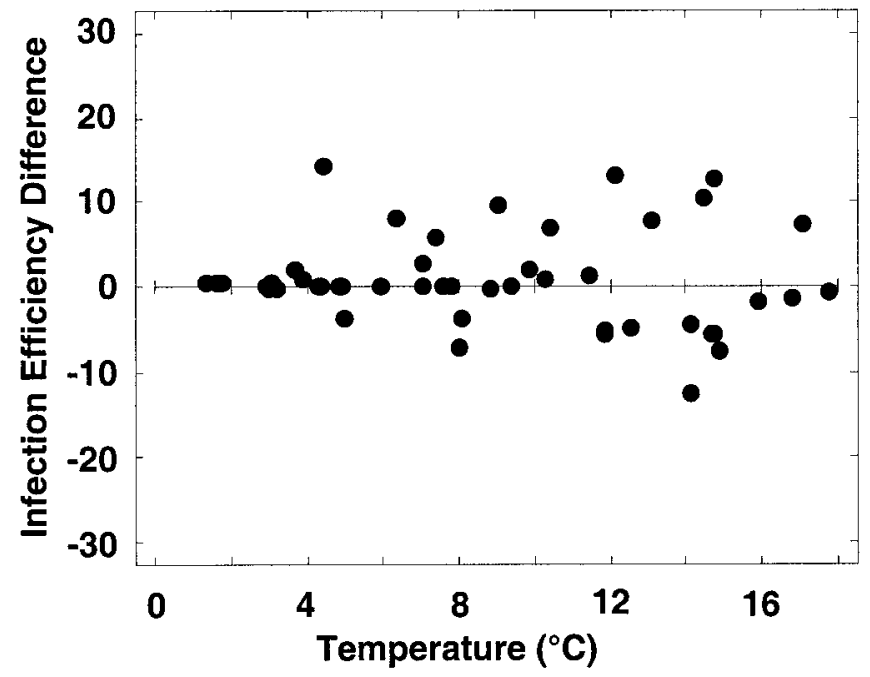

Fig. 5. Differences between observed and adjusted Puccinia striiformis infection efficiencies as a function of temperature. The adjustment of Model 1 to IE measurements in experiment 1 was made using preinoculation light quantity, postinoculation temperature, and postinoculation dew period $\left(r_{1}=\right.$ 0.80). IEs were observed in experiment 1 for 49 field tests with wetness caused by dew in the absence of rain. quanta $\mathrm{m}^{-2}$ were needed to produce an IE over $20 \%$. A Richards' function (equation 2) was fitted to the relationship between $L$ and $\mathrm{IE}$ (Fig. 4A). The resulting parameters (equation 3) were $\mathrm{IE}_{\max }=$ $42.1 \%, c=0.045$, and $d=-0.065$ with $r=0.96$. $\mathrm{IE}_{\max }$, equal to the asymptotic value of equation 3 , was higher than the maximum observed value of IE in both controlled-environment experiment 2 (36\%) and field experiment $3(30 \%)$ with preinoculation light quantity of 30.1 and $34.9 \mathrm{~mol}$ quanta $\mathrm{m}^{-2}$, respectively, and postinoculation at $8^{\circ} \mathrm{C}$ with 24 -h dew period.

In field experiment 3, the IE was in the range of 0.9 to $30 \%$. The Richards' function derived from the controlled-environment experiment 2 also described the field data of experiment $3(r=$ 0.91; Fig. 4B). Thus the light response curves for controlled conditions and the field appeared to be identical (Fig. 4).

Modeling preinoculation light quantity effect. Model 0 was modified to incorporate a term describing the effect of light quantity on IE for $P$. striiformis (equation 1 ) by including a relative infection efficiency term for light, $\operatorname{RIE}(L)$. $\operatorname{RIE}(L)$ was defined by the Richards' function described above (equation 3), with parameters derived from the controlled-environment experiment 2. Parameters defining the relative infection efficiencies, $\operatorname{RIE}(T)$ and $\operatorname{RIE}(D P)$, were derived from experiment 1 . Estimated values of the parameters defining $\operatorname{RIE}(T)$ (equation 4) were $n=0.87, m=$ $0.41, p=2.24, T_{\min }=2.37^{\circ} \mathrm{C}$, and $T_{\max }=19.8^{\circ} \mathrm{C}(r=0.96)$. The values of the parameters defining $\operatorname{RIE}(D P)$ (equation 6) were estimated to be: $D P_{\min }(T)=10.14-1.024 T+0.0427 T^{2}$ and $b(T)=$ $-0.023+0.0246 T-0.00101 T^{2}$. The adjustment of Model 1 to infection efficiencies observed in the field experiment 1 (Fig. 5) was compared to the predicted infection efficiencies made using Model 0 (Fig. 3), and presented as a function of temperature during the dew period. Model 1 fitted the field results of experiment 1 much better than Model 0 , with $r_{1}=0.80$ compared to $r_{0}=0.22$.

\section{DISCUSSION}

The parameters of Model 0 (8) were estimated using controlledenvironment experiments for predicting the effects of postinoculation temperature and dew period on infection efficiency. In the present study, field results for $P$. triticina confirmed the effectiveness of Model 0 for predicting leaf rust infection efficiencies. In the field experiments (in the range of 7 to 35 mol quanta $\mathrm{m}^{-2}$ ), there was no effect of light quantity on $P$. triticina infection efficiency. Model 0 has been included in a forecasting scheme (28) and is being used by Italian extension services for wheat leaf rust (9). For stripe rust however, attempts to use Model 0 to estimate the occurrence of infection in the field were unsuccessful.

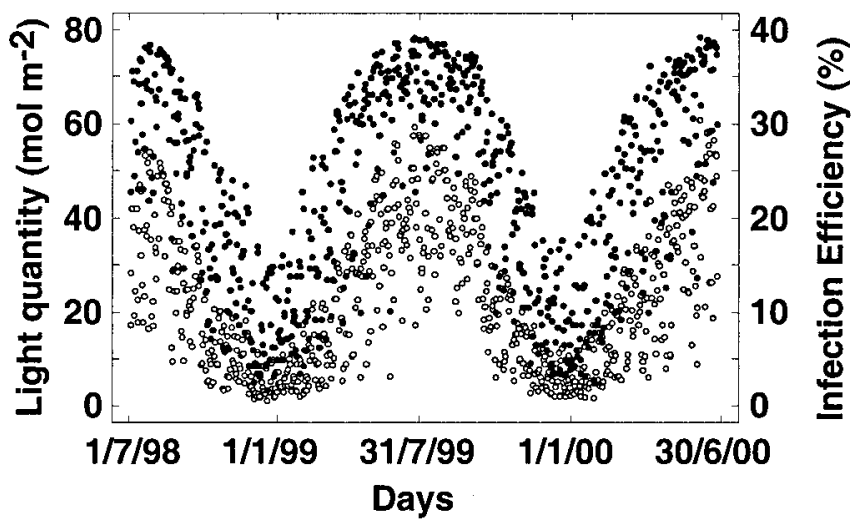

Fig. 6. Daily light quantity $(O)$ measured during 2 years at Grignon, France and simulated infection efficiency $(\bullet)\left\{\operatorname{IE}(L)=\operatorname{IE}_{\max } \times \operatorname{RIE}(L)\right\}$ using equation 3 for the corresponding daily light quantities with $\mathrm{IE}_{\max }=42.1 \%, c=$ 0.045 , and $d=-0.065$. 
For example, we have observed that two nights might be similar in average temperature $\left(9.4\right.$ and $10.3^{\circ} \mathrm{C}$ on 16 March and 21 May, respectively) and dew period (over $13 \mathrm{~h}$ each night), but the first night resulted in low infection (5\%) and the second night in high infection $(20 \%)$ for $P$. striiformis. In the first case, the plants received $6.1 \mathrm{~mol}$ quanta $\mathrm{m}^{-2}$ the day before infection and in the second case, 35.4 mol quanta $\mathrm{m}^{-2}$. Model 1, which integrates a third microclimate variable, the light quantity received by plants on the day before inoculation, was fitted much better to field data than Model 0. Under both controlled and natural conditions, values of $P$. striiformis infection efficiency were in the range of 0.4 to $36 \%$, and increased as a function of light quantity received by the plants before inoculation. For $P$. striiformis, a 16 h-darkness period before inoculation was detrimental to the infection. Light-dependent relationship was a Richards' function (equation 3 ) assessed under controlled conditions and validated in the field. Infection efficiency was, therefore, described as the product of maximum infection efficiency $\mathrm{IE}_{\max }$ under optimal conditions and three modulating functions of temperature, dew period, and light quantity. For stripe rust, field experiments were used to estimate the temperature-dependent parameters of Model 1, which was afterward fitted to experimental data. In the case of stripe rust, Model 1 should be validated with another independent set of field experiments.

The effect of light may explain temporal variation in the infection efficiency of $P$. striiformis. The daily radiation totals measured in the field over a 2-year period at Grignon, France (Fig. 6) exhibited a marked seasonal variability, with a maximum of 61 mol quanta $\mathrm{m}^{-2}$ during the spring months and minimum of $0.8 \mathrm{~mol}$ quanta $\mathrm{m}^{-2}$ during the autumn months. There was also a large variation between days (18 to $59 \mathrm{~mol}$ quanta $\mathrm{m}^{-2}$ for June and 2.2 to 22 mol quanta $\mathrm{m}^{-2}$ for February). Infection efficiency simulated using light quantity values with equation 3 was in the range of 1.5 to $40 \%$, suggesting that preinoculation light quantity may cause daily and seasonal variations in $P$. striiformis infection efficiency. Indeed, this disease is known to be sporadic (17).

Environmental factors affecting infection efficiency, such as temperature and wetness duration, have been investigated extensively (18), whereas the effect of light quantity has received little attention (23). For $P$. striiformis, reduction of light intensity during the postinoculation period induced an increase in infection type on certain host cultivars (36) and on certain race-cultivar combinations (5). There have been a few reports of the effect of preinoculation temperature on infection. The effectiveness of certain temperature-sensitive resistance genes was shown to be lowered when seedlings were raised either at high or low temperatures before inoculation (35). A preinoculation influence of light intensity on infection was observed on a $P$. striiformis race-wheat cultivar combination (36) and on three of six wheat cultivars tested with Puccinia graminis Pers.:Pers. f. sp. tritici Eriks. \& E. Henn. (3). The influence of low radiation was also noticed when plants that were grown under low light intensity did not show expected rust infection (39), but the phenomenon was never quantified. In this case, light quantity received by the plants influenced variation in host receptivity to stripe rust, whereas postinoculation temperature and dew period influenced both the host and the pathogen as they interact in the infection process.

High $P$. striiformis infection occurred in field experiments when the dew period was adequate, even when the temperature was high $(25,38)$. The night temperatures were higher than the maximum temperature determined under laboratory experiments $(8,25)$, fluctuating from 19 to $30^{\circ} \mathrm{C}(25)$ and reaching $20^{\circ} \mathrm{C} \mathrm{(38)}$. As temperature is usually correlated with high radiation levels, high infection efficiencies observed when temperatures were high may be the result of radiation effects.

Preinoculation light quantity affected host receptivity. Effects of preinoculation light quantity might extend longer than a day prior to inoculation. For plants that have received a 16 -h-dark period before inoculation with either low light quantity (experiments 2 and 3) or high light quantity (unpublished data) the previous day, observed IEs were $<2$ and $10 \%$, respectively. However, in both cases, when high light quantity $\left(>30 \mathrm{~mol}\right.$ quanta $\mathrm{m}^{-2}$ ) was received just before inoculation, the maximum IEs were similar (over $30 \%$ ).

This work provides a better understanding of the biology of $P$. striiformis. P. triticina and $P$. striiformis have been characterized as having high and low potential infection efficiency, respectively. High sporulation per lesion due to systemic growth within the leaf for $P$. striiformis was thought to compensate low infection efficiency (32). The present study showed that host receptivity was sensitive to radiation for wheat stripe rust but not for wheat leaf rust, and that under optimal temperature and dew conditions with sufficient light quantity, both rusts had the same high potential infection efficiency (over 30\%).

The increase of available leaf tissue improves the reproductive success of rust fungi over the spring months. During this period, light quantity is higher and host receptivity to $P$. striiformis increases. $P$. striiformis life cycle is therefore synchronized with that of its host for both food supply and reproduction and makes the pathogen development highly linked to host growth.

The infection process of $P$. striiformis is more sensitive than is the process in other cereal rusts (17). P. triticina spores can germinate and infect if temperature and dew period are adequate, which is often the case. However, infection by $P$. striiformis spores is clearly favored when host receptivity is enhanced by large amounts of preinoculation light, which is likely to occur during prolonged clear sky meteorological conditions that favor nocturnal dew formation and its persistence in the morning.

Our work provides a better understanding of the initial establishment of infection by $P$. striiformis. Fungal penetration was increased if leaves had previously received high light quantity. However, penetration takes place in darkness through closed stomata (8), suggesting that it is not the opening of stomata but some other light-controlled phenomenon that is implicated. Similar observations of light effect on infection have been made for zoospores of Pseudoperonospora humuli Miy. \& Tak. (Wilson) and of Plasmopara viticola (Berk. \& Curt. Ex de Barry) Berl. \& de Toni on leaf disks of hop and grapevine, respectively (29). Light may be mediating a signal (e.g., a chemical compound) for the attraction of the germ tubes by stomata.

These results also point out the need for field experiments to verify the relationship established under controlled conditions between epidemiological variables and environmental factors (20). Contradictory results discovered on $P$. striiformis infection efficiency under controlled-environment and field experiments pointed out the importance of preinoculation light quantity on plants. Many studies on infection have been concerned with controlled conditions and modeling, and little attention has been given to the applicability of results to natural field conditions.

Stripe rust has been considered a cool-weather disease. This research indicates that high temperatures are not necessarily detrimental if the plants have received sufficient light. Further research is needed to clarify the respective roles of preinoculation light and postinoculation temperature. In particular, the effect of preinoculation light quantity on infection efficiency should be further examined in controlled conditions at various temperatures as the present results suggested positive interaction between preinoculation light quantity and postinoculation temperature. The highest P. striiformis infection efficiency was observed when the temperature was $14.5^{\circ} \mathrm{C}$ and preinoculation light quantity $28.8 \mathrm{~mol}$ quanta $\mathrm{m}^{-2}$. In conditions of darkness before inoculation, highest infection efficiency was obtained at $8^{\circ} \mathrm{C}$.

\section{ACKNOWLEDGMENTS}

We thank A. McCartney for helpful comments. 


\section{LITERATURE CITED}

1. Analytis, S. 1977. Über Die Relation Zwischen Biologischer Entwicklung Und Temperatur Bei Phytopathogenen Pilzen. Phytopathol. Z. 90:64-76.

2. Anikster, Y., Bushnell, W. R., Eilam, T., Manisterski, J., and Roelfs, A. P. 1997. Puccinia recondita causing leaf rust on cultivated wheats, wild wheats, and rye. Can. J. Bot. 75:2082-2096.

3. Brown, J. F., and Shipton, W. A. 1964. Some environmental factors influencing penetration from appressoria of Puccinia graminis f. sp. tritici on seedling wheat leaves. Phytopathology 54:949-951.

4. Calonnec, A., Goyeau, H., and de Vallavieille-Pope, C. 1996. Effects of induced resistance on infection efficiency and sporulation of Puccinia striiformis on seedlings in varietal mixtures and on field epidemics in pure stands. Eur. J. Plant Pathol. 102:733-741.

5. Calonnec, A., Johnson, R., and de Vallavieille-Pope, C. 1997. Identification and expression of the gene $\mathrm{Yr} 2$ for resistance to Puccinia striiformis in the wheat differential cultivars Heines Kolben, Heines Peko and Heines VII. Plant Pathol. 46:387-396.

6. Clifford, B. C., and Harris, R. G. 1981. Controlled environment studies of the epidemic potential of Puccinia recondita f. sp. tritici on wheat in Britain. Trans. Br. Mycol. Soc. 77:351-358.

7. de Vallavieille-Pope, C., Picard-Formery, H., Radulovic, S., and Johnson, R. 1990. Specific resistance factors to yellow rust in seedlings of some French wheat varieties and races of Puccinia striiformis Westend. in France. Agronomie 10:103-113.

8. de Vallavieille-Pope, C., Huber, L., Leconte, M., and Goyeau, H. 1995. Comparative effects of temperature and interrupted wet periods on germination, penetration, and infection of Puccinia recondita f. sp. tritici and $P$. striiformis urediniospores on wheat seedlings. Phytopathology 85:409-415.

9. de Vallavieille-Pope, C., Giosue, S., Munk,L., Newton, A. C., Niks, R. E., Østergård, H., Pons-Kühnemann, J., Rossi, V., and Sache, I. 2000. Assessment of epidemiological parameters and their use in epidemiological and forecasting models of cereal airborne diseases. Agronomie 20:715-727.

10. Dennis, J. I. 1987. Temperature and wet-period conditions for infection by Puccinia striiformis f. sp. tritici race 104E137A+. Trans. Br. Mycol. Soc. 88:119-121.

11. Eversmeyer, M. G., Kramer, C. L., and Hassan, Z. M. 1988. Environmental influences on the establishment of Puccinia recondita infection structures. Plant Dis. 72:409-412.

12. Eyal, Z., Clifford, B. C., and Caldwell, R. M. 1968. A settling tower for quantitative inoculation of leaf blades of mature small grain plants with urediospores. Phytopathology 58:530-531.

13. Gassner, G., and Straib, W. 1928. Untersuchungen Über Die Infektionsbedingungen Von Puccinia glumarum und Puccinia graminis. Arb. Biol. Reichsanst. Land Forstwirtsch. 16:609-629.

14. Gassner, G., and Straib, W. 1932. Die Bestimmung Der Biologischen Rassen Des Weizengelbrostes (Puccinia glumarum f. sp. tritici (Schmidt) Erikss. u. Henn.). Arb. Biol. Reichsanst. Land Forstwirtsch. 20:141-163.

15. Geagea, L., Huber, L., and Sache, I. 1999. Dry-dispersal and rain-splash of brown (Puccinia recondita f.sp. tritici) and yellow (P. striiformis) rust spores from infected wheat leaves exposed to simulated raindrops. Plant Pathol. 48:472-482.

16. Hassebrauk, K. 1970. Der Gelbrost Puccinia striiformis West. 2 Befallsbild. Morphologie und Biologie der Sporen. Infektion und Weitere Entwicklung. Wirkungen Auf Die Wirtspflanze. Pages 1-111 in: Mitt. Biol. Bundesanst. Land Forstwirtsch. Berlin.

17. Hau, B., and de Vallavieille-Pope, C. 1998. Wind-dispersed diseases. Pages 323-347 in: The Epidemiology of Plant Diseases. D. Gareth-Jones, ed. Kluwer Academic Publishers, Dordrecht, the Netherlands.
18. Huber, L., and Gillespie, T. J. 1992. Modeling leaf wetness in relation to plant disease epidemiology. Annu. Rev. Phytopathol. 30:553-577.

19. Johnson, D. A. 1980. Effect of low temperature on the latent period of slow and fast rusting winter wheat genotypes. Plant Dis. 64:1006-1008.

20. Kranz, J., and Rotem, J. 1988. Experimental Techniques in Plant Disease Epidemiology. Springer-Verlag, New-York.

21. Little, R., and Manners, J. G. 1969. Somatic recombination in yellow rust of wheat (Puccinia striiformis). I. The production and possible origin of two new physiologic races. Trans. Br. Mycol. Soc. 53:251-258.

22. Manners, J. G. 1950. Studies on the physiologic specialization of yellow rust (Puccinia glumarum (Schm.) Erikss. \& Henn.) in Great Britain. Ann. Appl. Biol. 37:187-214.

23. McCartney, H. A. 1997. The influence of environment on the development and control of disease. Pages 3-31 in: Environmentally Safe Approaches to Crop Disease Control. N. A. Rechcigl and J. E. Rechcigl, eds. Lewis Publishers, CRC Press LLC, New York.

24. Mehta, Y. R., and Zadoks, J. C. 1970. Uredospore production and sporulation period of Puccinia recondita f. sp. triticina on primary leaves of wheat. Neth. J. Plant Pathol. 76:267-276.

25. Park, R. F. 1990. The role of temperature and rainfall in the epidemiology of Puccinia striiformis f. sp. tritici in the summer rainfall area of eastern Australia. Plant Pathol. 39:416-423.

26. Pieschel, E. 1931. Erfahrungen Über Einsporimpfungen Mit Getreiderostpilzen. Phytopathol. Z. 3:89-100.

27. Pyzhikova, G. V. 1975. On the sporulation of Puccinia striiformis West. f. sp. tritici, the cause of wheat stripe rust. (In Russian) Mikol. Fitopat. 9:228-230.

28. Rossi, V., Racca, P., Giosuè, S., Pancaldi, D., and Alberti, I. 1997. A simulation model for the development of brown rust epidemics in winter wheat. Eur. J. Plant Pathol. 103:453-465.

29. Royle, D. J., and Thomas, G. G. 1973. Factors affecting zoospore responses towards stomata in hop downy mildew (Pseudoperonospora humuli) including some comparisons with grapevine downy mildew (Plasmopara viticola). Physiol. Plant Pathol. 3:405-417.

30. Sache, I. 1997. Effect of density and age of lesions on sporulation capacity and infection efficiency in wheat leaf rust (Puccinia recondita f. sp. tritici). Plant Pathol. 46:581-589.

31. Sache, I., and de Vallavieille-Pope, C. 1993. Comparison of the wheat brown and yellow rusts for monocyclic sporulation and infection processes, and their polycyclic consequences. J. Phytopathol. 138:55-65.

32. Sache, I., and de Vallavieille-Pope, C. 1995. Classification of airborne plant pathogens based on sporulation and infection characteristics. Can. J. Bot. 73:1186-1195.

33. SAS Institute. 1990. SAS/STAT User's Guide. Vols. 1 and 2, Version 6, 4th ed. SAS Institute, Cary, NC.

34. Shaner, G., and Finney, R. E. 1980. New sources of slow leaf rusting resistance in wheat. Phytopathology 70:1183-1186.

35. Sharp, E. L. 1962. Effect of pre-inoculation host temperature on infection of cereal seedlings by Puccinia striiformis. Nature 194:593-594.

36. Stubbs, R. W. 1967. Influence of light intensity on the reactions of wheat and barley seedlings to Puccinia striiformis. Phytopathology 57:615-617.

37. Stubbs, R. W. 1985. Stripe rust. Pages 61-101 in: The Cereal Rusts. A. P. Roelfs and W. R. Bushnell, eds. Vol. II. Academic Press, London.

38. Tu, J. C., and Hendrix, J. W. 1967. The summer biology of Puccinia striiformis in southeastern Washington. I. Induction of infection during the summer. Plant Dis. Rep. 51:911-914.

39. Zadoks, J. C. 1961. Yellow rust on wheat. Studies in epidemiology and physiologic specialization. Tijdschr. Plantenziekten 67: 69-256.

40. Zadoks, J. C., Chang, T. T., and Konzak, G. F. 1974. A decimal code for the growth stages of cereals. Weed Res. 14:415-421. 